\title{
AN EMPIRICAL STUDY OF SELECTED INDIAN COMPANIES' TALENT MANAGEMENT
}

\author{
Shivani Raheja* \\ Aryabhatta College, University of Delhi (India) \\ shivaniraheja@hotmail.com \\ Dr. Deepak Jain \\ Amity College Florida, USA \\ prof.djain@gmail.com
}

\begin{abstract}
Talent Management is an organizational approach which companies feel allows them to maintain and enhance the performance of their highly gifted workers. It is an effective method to employ the appropriate talent and to prepare it to assume top positions in the future, to evaluate and manage its performance and also to keep it from leaving the company. The success of any organization, which analyses the skills retention strategy used by the IT sector in India, relies on the performance of its workers. And the research that address, Talent management, IT \& ITES Sector in India and based on a comprehensive literary evaluation of chosen IT businesses in India, as well as material gathered from primary and secondary sources. Indian IT Companies Talent Management, Talent Management at TCS, Infosys Talent Management, IBM Talent Management, Organization Development.
\end{abstract}

Keywords: talent management, organizational performance, it industry, MBA

\section{INTRODUCTION}

Over the years, talent management has developed and the expansion of the HR profession and its duties has been integrated into the organization's aims and strategy. Talent management has evolved from an administrative procedure to a corporate practice with a strategic focus that leads to organizational results. The capacity to develop and utilize talent to accomplish corporate goals is talent management. The word includes a variety of skills such as technology, management, etc. The established practice of talent management is the use of linked human resources procedures to provide every company a basic core advantage.

Talent Management focuses on all elements of the development of human resources in order to create the highest workforces in order to achieve their objectives in customer service by the company and the individual workers. Organizations offer many possibilities both within and outside the workplace for personnel or growth.

Talent management is the management of employee's human ability, skills and power. Talent management in the company does not only attract the finest and most efficient individuals to the business, but it is also an ongoing process including the procurement, recruitment, development, maintenance and support of people while fulfilling the needs of the organization. The organization is taken to the next level by the human resource. The most essential thing is to discover excellent talent, achieve success and long-term survival in company. The following stage, based on the person's skills, knows how, skills, ability and competency, is to attract and strategically integrate the greatest people into the company. Recruiting a person in an incorrect position not only undermines the organization's 
goal but also kills the individual's interest, ability and competence. When the company cannot match the appropriate individual to the correct position, the talent management process is inadequate.

The job of managers is even more crucial to success, given that businesses operate in an increasingly complicated environment where new and diverse problems lie. In order to achieve and further business goals, the development of managers and other important personnel is necessary. More and more people are essential to success inside businesses. At the core of the development of talent management is the need to identify, create and implement succession plans, enhance recruiting and retention of such people. In recent decades, the management of talent has evolved considerably. There has been a lot of discussion, study and development about the role, value, methods and application of talent management.

\section{Talent Management}

$\mathrm{HR}$ is the sum of the inherent abilities, knowledge and skills of the talents and capabilities of the company's workers. To accomplish individual and corporate objectives, human resources should be used to the fullest. The performance and productivity of an organization are directly proportionate to its human resources in terms of number and quality. This is why there has been a very strong professional and academic interest in the idea of talent management. The process of recruitment, formation, the development, management, evaluation and retention of the most important asset of a company may be described as Talent Management. Talent management is one of the leading drivers of success and development in this competitive industry. Organization, before their rivals, should be able to anticipate and take advantage of new possibilities. Talent Management has therefore become a new problem for the next generation of "people managers" in the present situation. The organizations need to connect their people management efforts with their business objectives has become increasingly essential on this competitive market. Such a culture should also be encouraged where exceptional workers have plenty of career growth chances to achieve to the highest degree. It is the only top/class talent that adds to the productive nature of the company, contributing to revenues via value creation for its customers. As performance and success for all organizations depends on how the organization manages and maintains its talent group, the best talent management practices in the industry should be implemented to help the organization gain a competitive edge over competitors and also help the company stay on the market always. The talent management process includes all key elements of the "life cycle" of an employee which including recruiting and selection, improving their knowledge via suitable training, performance management and succession planning for the future. Top Management and HR managers have long concentrated on fundamental talent management, but they need dedicated, committed and high-performance workers to achieve the required levels of success. Clearly, the corporation's most significant assets are people and therefore, the company adopts various methods of building data oriented decision-making platforms.

\section{The companies are helped by a strategy for talent management:}

- Be "proactive" instead than "reactive" and also take adjustments immediately.

- Identify the necessary skills and skills needed in all workers, and therefore reduce cost of training, with focus on the main and important areas of growth.

- Enhance the recruiting process by differentiating high-quality applicants via job descriptions based on the skills of high performing staff with highly valued enterprise or industrial skills.

- Helps the company to reduce attrition, since with its talent management efforts it will succeed in maintaining its top/key personnel.

- Enables the organization's performance, productivity and revenue or profitability to grow enormously. 


\section{IT \& ITES Sector in India}

The Indian IT \& ITES sector has been steadily growing in recent years and more particularly, it has driven the country's economic revolution and changed India's image in the global economy. India continues to be at the heart of its distinct demographic and cost competitiveness proposal on the worldwide sourcing market (Indian Brand Equity Foundation - IBEF) IT sector in India accounted for approximately 7,7\% of GDP in India (Gross Domestic Product). In India, ITES grew from USD 74 billion in FY10, which in turn rose 3-4 times more than the worldwide ITES growth, by $10.71 \%$ to US\$167 trillion in FY18E. The business is projected to expand to 350 billion dollars by 2025. (IBEF).

\section{Talent Management in Indian IT Companies}

Building and maintaining a strong talent is one of the major difficulties for IT businesses worldwide, Not only must companies be adapted to change demographics and preferences for the workforce, they also need to develop new capacities, management and human resources management have consistently focused on fundamental talent management that employs, hires and retains talent. But company leaders must include high-performance workers to promote optimum success levels. The finest individuals across the globe are one of the key components of a successful company. Some of the businesses and their involvement in talent management are below to preserve the finest skills.

\section{Talent Management at TCS:}

Tata Consultancy Services (TCS), which provides the most precious asset to individuals, is India's biggest ICT (IT) and BPO (Business Process Outsourcing) provider. Talent management teams know the abilities and skills of all their workers to make more informed planning, training and delivery choices.

- TCS has altered their recruitment approach to create a quality talent pool by concentrating on just-in-time recruitment or real time talent management.

- TCS launched an academic interface programme, and also a range of courses such as Learning and Development, Initial Learning, Continuous Learning Programs, Leadership Development Programs, Foreign Language Initiative, Workplace Learning and Ignite, were offered by TCS.

- The TCS compensation management system is built on the concept of economic added value (EVA).

- TCS performs twice a year an assessment of its normal staff as well as after the conclusion of the project for workers specially recruited for different projects. TCS has acknowledged the work of its employees in various ways in order to recognize their exceptional potential.

- To manage a biodato database, the business has created the "Résumé Information Extractor" (RINX), a tool used to update the organization's knowledge store in real time by using textmining, automation, natural linguistics processing, data mining and information recovery technology.

- TCS now has an upgraded employee knowledge base, which allows managers to identify applicants for certain jobs, projects or activities quickly and accurately.

\section{Talent Management at Infosys:}

As an Indian global technology company, Infosys Technologies is based in Bangalore with its headquarters. For 2011, Infosys ranks 27th on Fortune India's list of India's top enterprises 500. It has offices in 29 countries in various nations and centers for development. It offers consulting services for companies, technologies, engineering and outsourcing in over 30 countries. Many investigations of the company's HR procedures, one of which was done by Elisa Tucker and Rachel Williams, were published on May 2011. It says that high performance firms such as Infosys focus on the management of talent. One of these practices is the commitment of employees, part of the talent management process. The procedure includes:

- Create and convey an official employment brand to staff. 
- Creating a favorable brand image for an outside business (e.g., awards as best place to work or best place for leaders).

- Locally use excellent talent (where applicable).

- Allow workers to be heard informally and officially via grievance redressing programmes, through social media sites.

- Selection of employees: Use high potential or value to attract new employees and choose them.

- Training and development: educate managers and leaders on employee engagement concepts.

- Teach the basic principles of talent management to new managers and supervisors.

- Providing meaningful and adaptable career pathways to workers which enable the company to feel its purpose and guidance, and offer individuals with an element of challenge.

\section{Talent management at IBM:}

A collaborative research performed by IBM and Human Capital Institute examined 1,900 people in more than 1,000 commercial and public sector organizations, worldwide, on the management of their talent and selected a handful of them.

- Develop strategy: Development, development and deployment of an optimum long term plan for employees.

- Attract and retain: Source, attract and rely on the talents and skills suitable to company requirements.

- Motivation and development: to verify that people's skills are understood and developed in line with company demands while satisfying the motivation, development and work satisfaction needs of individuals.

- Deployment and management: to ensure the efficient use of resources, planning and work management in line with organizational requirements.

- Connect and enable: identification, collaboration and information exchange, successful work in the virtual environment of people with appropriate talents.

- Transform and sustainability: achieve clear, quantifiable and sustainable transformation inside the company while preserving day-to-day operational continuity.

\section{Talent Management System Features Highlights}

Connecting and sharing data: Core HR operations may be integrated and coordinated by the appropriate Talent Management System (TMS). While much data gathered by HRIS are kept in silos and cannot be reached and analyzed easily, an integrated TMS distributes information throughout the whole system that allows simple access. This allows you to comprehend more clearly what this data means to your company and to make educated, strategic choices.

Strategic Hiring Process: A TMS can assist the organization, after all, to attract these exceptional individuals. Through the integration of work descriptions, the tracks of applicants and the simple handling of offers, a TMS optimizes the recruitment process to give sufficient time to concentrate on the applications..

Retain Top Talent: It's important to retain them after the company has the finest staff. With all the information provided by workers on one platform and clearly arranged into an online profile, performance evaluations, objectives, skills and career ambitions can be pursued to ensure people are satisfied and on the correct road. With a TMS that collects all these data, it is simple to evaluate and report on which staff needs to grow, monitor or even promote.

Employee Development: A properly integrated TMS should offer staff development and learning opportunities. It allows staff to attend courses, acquire competences and, in certain instances, to seek certifications that are important for their career growth. TMS systems also gather data on an 
employee's abilities and provide the HR team with training that the employee may access from his or her personal profile.

Improved Employee Experience: As we know, the turnover of staff can at all costs be prevented. A payroll TMS enhances your experience by providing access to pay-slips vacation requests and sick leave management. The company's reporting and management structure may also be incorporated in Organizational charts.

Increase Employee and Manager Engagement: TMS is one of HR's finest methods for effectively involving workers and management. The staff profile enables staff and managers to engage with the development of their professional careers. An integrated TMS solution encourages them to invest in the business and to focus on their day-to-day work on business goals.

\section{Organizational Performance}

One of the major problems confronting management today is the development and retention of a workforce which contributes to the success of the organizations. The primary aim of any business is to achieve continuous and regular performance in order to develop and advance in this competitive market. Therefore, organizational performance is the most essential criterion to assess the organizations and their activities. Corporate performance may be described as a financial and nonfinancial indicator that gives information about the degree of attainment of its goals and aims. When all its components work together to produce huge outcomes, corporate performance is regarded to be excellent and these results will be evaluated by the value it creates and provides to consumers. To optimize productivity and overall corporate success, any business requires skilled workers. Only when their human resources are inventive and creative are they able to acquire a lasting competitive edge over their rivals. When assessing the global market as a whole, businesses reach their market position and create ideal business results if they put importance to developing themselves, their employees and offering unique goods and services to their clients. To accomplish that, companies need to discover the talent, evaluate its potential, and therefore develop their abilities. Some variables are discovered by researchers that contribute to the companies' performance:

Continuous learning: Organizations must create specific methods to assist their staff learn, learn and learn. Such a culture enables companies to become very successful in the market.

Focusing on the customer results/outcomes: Organizations must concentrate on their consumers' value. If the consumers are happy, the income and organization's performance naturally increase.

Aligning systems and structures: If organizations' performance has to be harmonized with their systems, structures and all processes, and with their vision and purpose, with business objectives and strategies.

Employee involvement: Organizations should strive to have a high level of employee participation. It can accomplish this by empowering its brilliant workers to take their own choices, recognizing their creativity and their unique ideas and also motivating them to perform better.

Information sharing: Open communication should take place in the organization and the information should also flow freely. Employees should be informed of any changes and choices that are done, which will improve the performance of the organization. Both in financial and financial terms, organizational performance may be assessed. Financial indicators which indicate whether or not the company performs successfully include investment returns, strong revenues, sales growth and a high market share. On the other side, corporate performance non-financial indicators include employee happiness, customer contentment, less complaints, excellent connection with suppliers and also management confidence amongst workers. If the company performs well in both these categories, it may also be called a very successful organization. The participation of the skilled staff is essential to drive this high performance, since it is the main skills and assets a business has. The organization's 
human or intellectual capital helps it reach its aims and goals, and generates above average returns and excellence.

\section{Management Development}

In the course of the shortage of management talent groups on the labor market, the changing organizational structure and at the same time the rapid growth of globalization increased demand for skilled, talented managers, making management development a significant means of developing and retaining skilled and talented managers. The growth of management is a driver of competitive advantage and an essential part of manpower policies. It is acquiring the next stage of theory development despite the essential function of management development. The concept of management development among academics is quite different and empirical research is also lacking. Organisation, like other HR practices like HPWS (high performance-work system and more particularly selection, training, and recompense system, were left behind in research progress without an integrated perspective of MD. There is more confusion in literature with mixed empirical findings on the development and organizational performance of management studies. Literature has shown the positive impact of management development on organizational performance. While some academics do not agree on the value creation via management development programmes, management research is mostly carried out in English-American and European settings and there is some understanding about the applicability of management development in other contexts. The requirements of management talent development are efficiently recognized and handled by extending their career pathways and choices. Managers are therefore keener to build particular competencies of a company.

Agency theory talent management is a technique used to adapt management or employee behaviour to company requirements. In addition, the talent development programmes, in line with the company plan, are tailored to address each unique need. Talent businesses' investments increase the knowledge, expertise and capacity of management, helping to improve the quality and innovations at work and also strengthen the company's intellectual capital. As intellectual capital is a key component of corporate capital, it increases the company's market worth. In the meanwhile, workers with superior understanding and abilities have been shown to be more productive at work, leading to greater revenues for businesses. Critical motivators of talent, dedication, and work satisfaction were identified for career development and choices. Qualified and talented individuals appreciate nonfinancial assistance, such as dynamic career paths, demanding jobs and room for invention and creativity, also inclined to grow. This enables businesses to develop their reputation and increase their appeal as employers of choosing and to communicate this strategy.

\section{CONCLUSION}

Talent management is a new topic that has gained considerable attention, particularly since1990, from academics and business. In the past, some study focus has been paid to the connection between talent management (TM) and organizational success. Literature, however, lacks a research that examines, from an organizational standpoint, the multi-dimensionality of talent management (TM) and its connection with organizational performance (OP). It's very important for organizations to find the critical positions of their organizations identify potential people within the organization and develop them to those current and future critical or key positions that have a significant impact on organizational performance for sustainability and competitiveness The study is the first to validate different TM dimensions empirically. Finally, we highlighted key components like a required support from the company (top management) and strategy to discover and make use of the organization's talent. Indian companies need to know the various nations' growth strategies. Talent management has an impact on an organization's culture, talent and income. The brand image of a company may be made or breaked. The technique of talent management has become a powerful strategy for any company. Any business requires the appropriate people, talent management techniques and their 
effect on IT sector organizational success. The study and the research above show that talent management is favorably linked with the organizational overall achievement.

\section{REFERENCES}

[1]. Anupam Rani, U. J. (2012). A Study of Talent Management as a Strategic Tool for the Organization in Selected Indian IT Companies. European Journal of Business and Management, 4, 20-28

[2]. Ashton, C., \& Morton, L. (2005). Managing talent for competitive advantage: Taking a systemic approach to talent management. Strategic HR review, 4(5), 28-31. Retrieved from https://www.emeraldinsight.com/doi/abs/10.1108/14754390580000819.

[3]. Chandrakanta Sahoo, V. P. (2010). Talent Management: Issues and Strategies. IOSR Journal of Business and Management, 29-34.

[4]. Chris Ashton, L. M. (2005). Managing talent for competitive advantage: Taking a systemic approach to talent management. Strategic HR Review, 4 (5), 28 - 31.

[5]. David M. Gichuhi, R. W. (2014). Talent Management; It's role on competitiveness of public universities in Kenya. IOSR Journal Of Humanities And Social Science, 19 (1), 100-105.

[6]. Jagathkar, A. (2019) "BUILDING INDIA, A COUNTRY OF INNOVATIONS", IARS' International Research Journal. Vic. Australia, 9(1). doi: 10.51611/iars.irj.v9i1.2019.99.

[7]. K. Janardhanam, N. M. (2011). Talent Management Practices in IT sector. International Journal of Research in Commerce, IT and Management, 1 (2)

[8]. Kavya Singh, S. S. (2012). Driving Forces and Emerging Challenges in Talent Management: A pathway to Organizational Success. International Journal of Advanced Research in Computer Science and Software Engineering, 2 (6), 117-121.

[9]. Raheja, S. (2020) "Relevance of Integrity, Morality and Ethics in the Contemporary World: Learnings from Shrimad Bhagavad Gita", IARS' International Research Journal. Vic. Australia, 10(1). doi: 10.51611/iars.irj.v10i1.2020.107.

[10]. Rao, E. and Goel, A. (2017) "Factors causing work related stress in the Hospitality Sector: A study of employees in three star hotels in Dehradun Region", IARS' International Research Journal. Vic. Australia, 7(1). doi: 10.51611/iars.irj.v7i1.2017.65.

[11]. Schehar Bano, M. A., \& Rehman, H. (2011). Study of the factors those impacts on talent management in the corporate sector of Islamabad, Pakistan. Far East Journal of Psychology and Business, 2 (1), 4-16.

[12]. Thota, V. k. (2013). Effective Talent Management Practices: A Strategy for Organizational Success. GRA- Global Research Analysis, 2 (11), 157-159

[13]. Yadav, S. (2018) "Growing Human Population and Sustainable Development", IARS' International Research Journal. Vic. Australia, 8(1). doi: 10.51611/iars.irj.v8i1.2018.87.

[14]. Yapp, M. (2009). Measuring the ROI of talent management. Strategic HR Review, 8 (4), 5-10. 
A MIT Y

Amity Journal of Professional Practices (AJPP) | ISSN 2769-5778

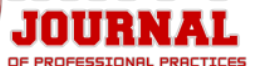

International Peer Reviewed Journal of Amity College Florida (USA)

Vol. 1 No. 1 (2021) | www.jconsortium.com/index.php/ajpp

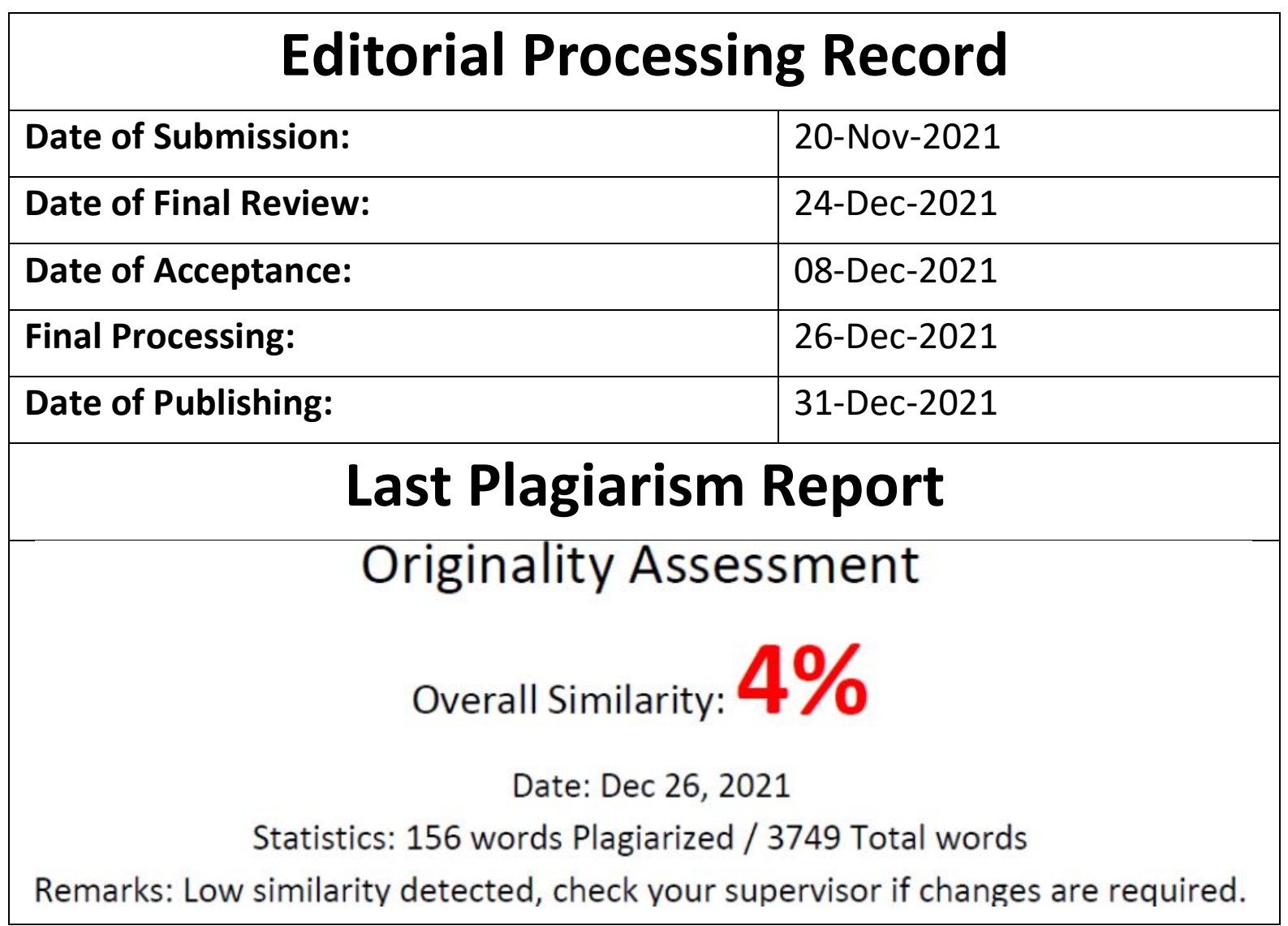

COPYRIGHT C AUTHORS 